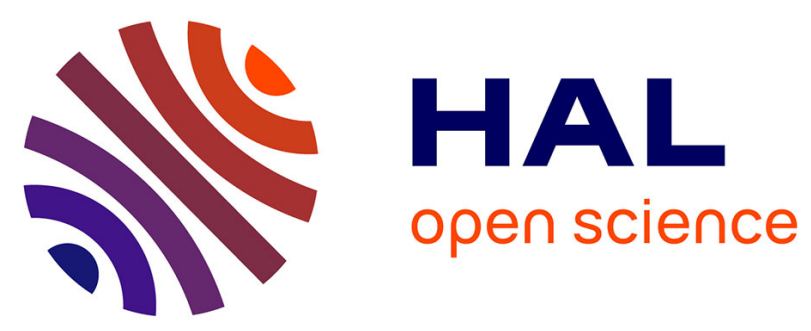

\title{
Evolution of noninvasive tests of liver fibrosis is associated with prognosis in patients with chronic hepatitis $\mathrm{C}$
}

Julien Vergniol, Jérôme Boursier, Clélia Coutzac, Sandrine Bertrais, Juliette Foucher, Camille Angel, Faiza Chermak, Isabelle Fouchard-Hubert, Wassil Merrouche, Frédéric Oberti, et al.

\section{To cite this version:}

Julien Vergniol, Jérôme Boursier, Clélia Coutzac, Sandrine Bertrais, Juliette Foucher, et al.. Evolution of noninvasive tests of liver fibrosis is associated with prognosis in patients with chronic hepatitis C. Hepatology, 2014, 60, pp.65-76. 10.1002/hep.27069 . hal-03329094

\section{HAL Id: hal-03329094 \\ https://univ-angers.hal.science/hal-03329094}

Submitted on 30 Aug 2021

HAL is a multi-disciplinary open access archive for the deposit and dissemination of scientific research documents, whether they are published or not. The documents may come from teaching and research institutions in France or abroad, or from public or private research centers.
L'archive ouverte pluridisciplinaire HAL, est destinée au dépôt et à la diffusion de documents scientifiques de niveau recherche, publiés ou non, émanant des établissements d'enseignement et de recherche français ou étrangers, des laboratoires publics ou privés. 


\title{
Evolution of Noninvasive Tests of Liver Fibrosis Is Associated With Prognosis in Patients With Chronic Hepatitis C
}

\author{
Julien Vergniol, ${ }^{1}$ Jérôme Boursier, ${ }^{2,3}$ Clélia Coutzac, ${ }^{1}$ Sandrine Bertrais,${ }^{3}$ Juliette Foucher, ${ }^{1}$ Camille Angel, ${ }^{2}$ \\ Faiza Chermak, ${ }^{1}$ Isabelle Fouchard Hubert, ${ }^{2,3}$ Wassil Merrouche, ${ }^{1}$ Frédéric Oberti, ${ }^{2,3}$ \\ Victor de Lédinghen, ${ }^{1,4}$ and Paul Calès ${ }^{2,3}$
}

No data are available about the prediction of long-term survival using repeated noninvasive tests of liver fibrosis in chronic hepatitis $\mathrm{C}(\mathrm{CHC})$. We aimed to assess the prognostic value of 3-year liver stiffness measurement (LSM), aspartate aminotransferase to platelet ratio index (APRI), and fibrosis 4 (FIB-4) evolution in CHC. CHC patients with two LSM (1,000-1,500 days interval) were prospectively included. Blood fibrosis tests APRI and FIB4 were calculated the day of baseline (bLSM) and follow-up (fLSM) LSM. Evolution of fibrosis tests was expressed as delta: (follow-up-baseline results)/duration. Date and cause of death were recorded during follow-up that started the day of fLSM. In all, 1,025 patients were included. Median follow-up after fLSM was 38.0 months (interquartile range [IQR]: 27.7-46.1) during which 35 patients died (14 liver-related death) and seven had liver transplantation. Prognostic accuracy (Harrell C-index) of multivariate models including baseline and delta results was not significantly different between LSM and FIB-4 $(P \geq 0.24)$, whereas FIB-4 provided more accurate prognostic models than APRI $(P=0.03)$. By multivariate analysis including LSM variables, overall survival was independently predicted by bLSM, delta (dLSM), and sustained virological response (SVR). Prognosis was excellent in patients having bLSM $<7 \mathrm{kPa}$, SVR, or no increase ( $<1 \mathrm{kPa} /$ year) in 7-14 kPa bLSM. Prognosis was significantly impaired in patients with an increase $(\geq 1 \mathrm{kPa} /$ year $)$ in $7-14 \mathrm{kPa}$ bLSM, or decrease ( $\leq 0 \mathrm{kPa} /$ year) in $\geq 14 \mathrm{kPa}$ bLSM $(P=0.949$ between these two groups). Patients with an increase ( $>0 \mathrm{kPa} /$ year) in $\geq 14 \mathrm{kPa}$ bLSM had the worst prognosis. Baseline and delta FIB-4 also identified patient subgroups with significantly different prognosis. Conclusion: Three-year evolution of noninvasive tests of liver fibrosis has a strong prognostic value in $\mathrm{CHC}$ patients. These tests should be repeated to monitor patients and predict their outcome. (Hepatology 2014;60:65-76)

$\mathrm{T}$ The evaluation of liver fibrosis is of major importance for the management of chronic liver disease and the prediction of prognosis, as complications occur in patients with advanced fibrosis stages. Progression to cirrhosis is associated with a risk of liver-related complications, hepatocellular carcinoma, and mortality. Monitoring of chronic liver disease is thus essential to identify progressive liver disease, start specific treatments, and decide on liver transplantation.
Currently, the reference for chronic hepatitis C (CHC) fibrosis evaluation and prognosis is liver biopsy, but due to complication rate, sampling error, intra- and interobserver variability, and expense, noninvasive methods are now preferred. ${ }^{1}$ In cirrhosis patients, Child-Pugh and MELD (Model of Endstage Liver Disease) scores are simple tools correlated with prognosis that help physicians to treat patients, monitor, and decide on liver transplantation. ${ }^{2,3}$ Among

Abbreviations: APRI, aspartate aminotransferase to platelet ratio index; BMI, body mass index; CHC, chronic hepatitis C; ELF, enhanced liver fibrosis test; LSM, liver stiffness measurement; MELD, Model for Endstage Liver Disease.

From the ${ }^{1}$ Centre d'Investigation de la Fibrose hépatique, Hôpital Haut-Lévêque, Centre Hospitalier Universitaire de Bordeaux, Pessac, France; ${ }^{2}$ Service d'Hépato-Gastroentérologie, Centre Hospitalier Universitaire d'Angers, Angers, France; ${ }^{3}$ Laboratoire HIFIH, UPRES 3859, SFR 4208, Université LUNAM, Angers, France; ${ }^{4}$ INSERM U1053, Université Segalen, Bordeaux, France.

Received September 29, 2013; accepted February 6, 2014. 
noninvasive diagnostic scores, Fibrotest (Biopredictive, Paris, France; Fibrosure-Labcorp, Burlington, VT), aspartate aminotransferase to platelet ratio index (APRI), enhanced liver fibrosis test (ELF), and fibrosis4 (FIB-4) are blood fibrosis tests that have been shown to be accurate in predicting the risk of liver complications and survival in various chronic liver diseases. ${ }^{4-14}$

Liver stiffness measurement (LSM) using $M$ probe of FibroScan (Echosens, Paris, France) is a simple noninvasive method for the management of chronic liver disease, available all over the world. Its performance for the diagnosis of fibrosis and liver-related complications is well established. ${ }^{15-21}$ LSM can predict the risk of hepatocellular carcinoma in chronic hepatitis B and C. ${ }^{22,23}$ It also displays a good predictive value for survival without liver-related death and overall survival in chronic hepatitis $\mathrm{B}^{22,24}$ In $\mathrm{CHC}$, we recently published the first study illustrating the 5-year prognostic value of LSM for predicting liver-related death and overall survival, in comparison with other methods. ${ }^{25}$

Evolution of fibrosis is a strong prognostic element in $\mathrm{CHC}$ and factors associated with progression are now well described. ${ }^{26}$ In clinical practice, there is a strong reluctance in repeating liver biopsies and a need for a prognostic surrogate marker for follow-up. Few data are available on fibrosis monitoring with repeated LSM. ${ }^{27-29}$ We have also recently shown that noninvasive tests might be more sensitive to detect fibrosis progression than liver biopsy even interpreted with morphometry. ${ }^{30}$ The first results in chronic hepatitis B or primary biliary cirrhosis showed that LSM evolution could predict liver-related events or death. ${ }^{31,32}$ To our knowledge, no study has evaluated and compared the effectiveness of repeated noninvasive tests of liver fibrosis in predicting long-term survival in $\mathrm{CHC}$ patients. We aimed to assess the prognostic value of 3-year LSM, APRI, and FIB-4 evolution in CHC.

\section{Patients and Methods}

\section{Patients}

We included all CHC patients who underwent a first LSM between January 2004 and February 2008 in the Hepatology Units of two tertiary centers (Haut-Lévêque Hospital, University Hospital of
Bordeaux, Pessac, France; University Hospital of Angers, Angers, France) and for whom a second LSM was available 3 years later. All patients were aged over 18. Determination of $\mathrm{CHC}$ was done using standard diagnostic criteria: detectable serum anti-HCV antibodies and HCV RNA. Exclusion criteria were coinfection with human immunodeficiency virus or hepatitis B virus, another cause of liver disease (except alcohol), failure of LSM, previous liver-related complication (ascites, hepatic encephalopathy, portal hypertension-related bleeding, portal vein thrombosis, and hepatocellular carcinoma), liver transplantation before inclusion or before follow-up LSM, and less than 6 months follow-up after the second LSM. The study protocol conformed to the ethical guidelines of the updated 1975 Declaration of Helsinki. Patients were enrolled after written informed consent was obtained. The study was registered at the ClinicalTrials.gov (Identifier: NCT01241227).

\section{Baseline}

At baseline, on the same day, we performed LSM and recorded clinical and biological data.

Clinical Parameters. For all patients, the following clinical parameters were gathered: gender, weight, height, body mass index (BMI), alcohol, tobacco and cannabis consumption, hypertension, and diabetes.

LSM. LSM was performed with the patient lying in dorsal decubitus, with the right arm in maximal abduction, on the right lobe of the liver, through intercostal spaces. The operator, assisted by a time-motion ultrasound image, located a liver portion at least $6 \mathrm{~cm}$ thick and free of large vascular structures. When the target area had been located, he pressed the probe button to begin the measurements. The measurement depth was between 25 and $65 \mathrm{~mm}$ using the M probe of FibroScan (Echosens, Paris, France). Ten validated measurements were performed on each patient. The results are expressed in $\mathrm{kPa}$. Only procedures with at least 10 validated measurements and an interquartile range (IQR) inferior to $30 \%$ of the median value were considered reliable. ${ }^{19,33,34}$ LSM was performed in both units by specialized nurses.

Blood Tests. For all patients, the following blood parameters were measured: platelet count, aspartate aminotransferase, and alanine aminotransferase. The APRI

Address reprint requests to: Prof. Victor de Lédinghen, Centre d'Investigation de la Fibrose hépatique, Service d'Hépato-Gastroentérologie, Hôpital HautLévêque, 33604 Pessac, France. E-mail: victor.deledinghen@chu-bordeaux.fr; fax: + 33557656445.

Copyright $(2014$ by the American Association for the Study of Liver Diseases.

View this article online at wileyonlinelibrary.com.

DOI 10.1002/hep.27069

Potential conflict of interest: Victor de Lédinghen: Echosens consultant; Paul Calès: Biolivescale consultant; no other authors have a potential conflict of interest. We disclosed to study participants potential investigator conflicts of interest. 
and the FIB-4 score were calculated according to published formulas. ${ }^{5,6}$

\section{Follow-up}

The follow-up evaluation (follow-up LSM, APRI, and FIB-4) was performed between 1,000 to 1,500 days, i.e., at least 3 years after baseline evaluation (Supporting Fig. s1). Study follow-up started the day of the follow-up evaluation and ended December 31 2011. Final analysis of the data was in April 2013. Patients had a conventional treatment of their disease during follow-up: the peg-interferon and ribavirin regimen was used according to EASL guidelines, ${ }^{35}$ and a few patients had antiviral treatments under evaluation. Patients were followed every 6-12 months, depending on the severity of the disease. Those developing liverrelated complication had a closer follow-up. Sustained viral response (SVR) was defined by a negative HCVRNA 6 months after the end of antiviral therapy.

At the end of follow-up, death status and causes of death were recorded for patients still followed in our units, or for those whose physician gave us the information. For the remaining patients we asked the French national register of deceased called RNIPP (Repertoire National d'Identification des Personnes Physiques) according to the protocol used in this case. For patients who were lost to follow-up before December 312011 and not retrieved in the national register of deceased, the follow-up was censored at the time of last information available. Transplanted patients were registered as dead at the date of liver transplantation.

Overall survival (including all cause of death and liver transplantation) was the primary endpoint. The secondary endpoint was survival without liver-related death (including death related to liver disease or liver transplantation).

\section{Statistical Analysis}

Results are expressed as mean $\pm S D$, or with median [1st and 3rd quartiles] when specified. We used the 7.0 $\mathrm{kPa}$ and $14.0 \mathrm{kPa}$ cutoffs for the diagnosis of significant fibrosis (Metavir $F \geq 2$ ) and cirrhosis. ${ }^{16,36,37}$ Because the time interval between baseline and follow-up fibrosis tests could vary between 1,000 to 1,500 days, their evolution was calculated as delta $=$ (follow-up result - baseline result) / time interval between baseline and followup measurements (year). Delta LSM was thus expressed as $\mathrm{kPa} /$ year and delta APRI or FIB-4 as unit/year.

Comparison of Prognostic Accuracy of Noninvasive Fibrosis Tests. We first determined prognostic models for each fibrosis test by using the regression formula of multivariate Cox models. These models included baseline and delta results of fibrosis tests
(Model \#1); baseline and delta results adjusted for SVR only (Model \#2); or baseline and delta results adjusted for SVR, age, sex, virus genotype, and BMI (Model \#3). The prognostic accuracy of each model was then determined using the C-index of Harrell. ${ }^{38}$ The Harrell Cindex is an extension of the area under the receiver operating characteristic (AUROC) for time-to-event (survival) data and evaluates the concordance between the predicted risk of event and the observed survival time. Its results vary from 0 to 1 : 1 shows a perfect concordance (discriminative power of the risk score), 0.5 shows random prediction, and a value less than 0.5 indicates discrimination in the opposite direction to that expected. The 95\% confidence interval (CI) of each Harrell Cindex was calculated by a bootstrap method, using 1,000 random samples (with replacement) of the same size as the original dataset. Paired comparisons of the $\mathrm{C}$-indexes were performed using a bootstrap resampling procedure as previously described. ${ }^{39}$ Briefly, the difference between the two C-indexes was calculated on each of the 1,000 bootstrap samples to obtain the bootstrap 95\% CI of the difference. Then the estimate of the standard error from this bootstrap distribution was used to calculate the standardized difference between the C-indexes and find the corresponding $P$-value.

Prognosis Assessment in Clinical Practice. To identify predictors of death, we first performed univariate analysis using the univariate Cox Model for quantitative variables and Kaplan-Meier curves with the log-rank test for qualitative variables. Significant variables were then introduced in a multivariate Cox Model, those with skewed distribution being already ln-transformed. Finally, we tested the interactions between the independent predictors: in case of significant interaction between two variables, we determined subgroups of patients according to one of the variables included in the significant interaction, and repeated multivariate analyses to identify the independent predictors of death in these subgroups. By stratifying patients according to independent predictor results, this method allowed us to depict how to use these predictors in clinical practice to assess prognosis.

Two-sided statistical tests were used for all analyses. $P<0.05$ was considered significant. Statistical analyses were performed using SPSS v. 18.0 software (IBM, Armonk, NY) and SAS 9.2 (SAS Institute, Cary, NC).

\section{Results}

Characteristics of Patients. In all, 1,502 patients with CHC and 2 LSM at 3-year intervals were included between January 2004 and February 2008 in 


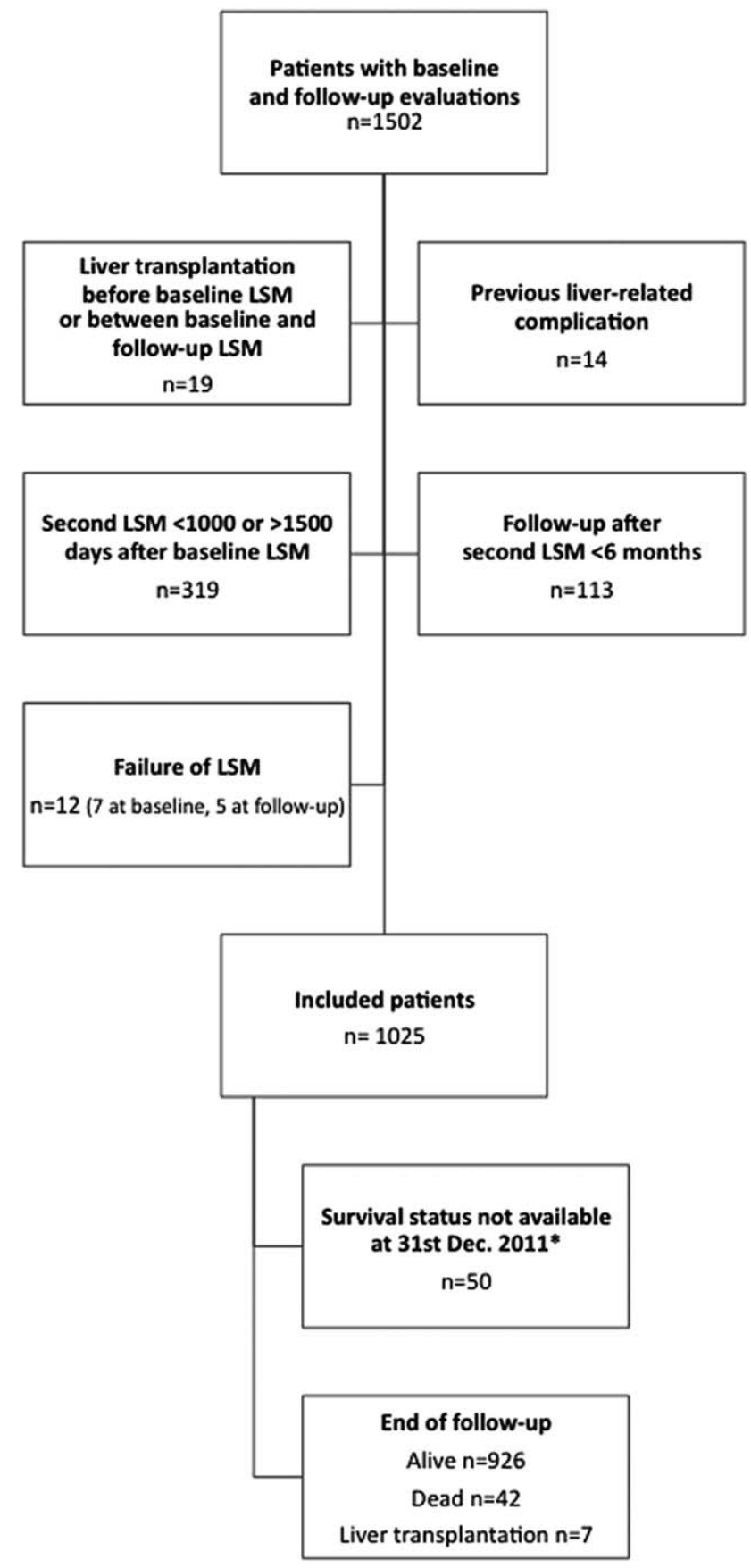

Fig. 1. Chart flow of patients. *For patients whose survival status was not available at 31 December 2011, follow-up was censored at the date of last information available. LSM: liver stiffness measurement, SVR: sustained viral response.

the Pessac and Angers centers. In all, 477 patients were excluded for: previous liver-related complications $(\mathrm{n}=14)$, liver transplantation before baseline LSM or between baseline and follow-up LSM $(\mathrm{n}=19)$, failure of baseline or follow-up LSM $(n=12)$, delay between baseline and follow-up LSM $<1,000$ or $>1,500$ days $(\mathrm{n}=319)$, less than 6 months follow-up after followup LSM ( $\mathrm{n}=113)$ (Fig. 1).
In all, 1,025 patients were finally included. Their characteristics are presented in Table 1 . The mean age was $52.0 \pm 12.0$ years; $49.7 \%$ of the patients were male; mean BMI was $24.5 \pm 4.0 \mathrm{~kg} / \mathrm{m}^{2}$; and $11.8 \%$ of patients had excessive alcohol consumption ( $>30 \mathrm{~g} /$ day for men and $>20 \mathrm{~g} /$ day for women). During follow-up, $16.4 \%$ patients achieved SVR. $56.0 \%, 31.3 \%, 12.7 \%$ of patients had baseline LSM, respectively: $<7 \mathrm{kPa}, \geq 7$, and $<14 \mathrm{kPa}, \geq 14 \mathrm{kPa}$. The time interval between baseline and follow-up LSM was $40.7 \pm 4.0$ months (median: 40.1 [1st and 3rd quartiles: 37.3-43.8]). Median baseline LSM was $6.6 \mathrm{kPa}$ [1st and 3rd quartiles: 5.1-9.5] and median follow-up LSM was $6.2 \mathrm{kPa}$ [4.88.8]. Baseline and follow-up LSM were significantly different $(P=0.014)$ and well correlated (Spearman correlation coefficient Rs $=0.650, P<0.001$; Supporting Table s1). Median delta LSM was $-0.1 \mathrm{kPa} /$ year [-0.6$0.4]$. As expected, IQRs of delta LSM were significantly wider as baseline LSM increased: $0.03 \mathrm{kPa} /$ year [-0.22$0.36]$ for baseline LSM $<7.0 \mathrm{kPa},-0.42 \mathrm{kPa} /$ year [-0.88-0.36] for baseline LSM between 7.0 and 14.0 $\mathrm{kPa}$, and $-1.13 \mathrm{kPa} /$ year [-2.76-1.24] for baseline LSM $\geq 14.0 \mathrm{kPa}(P<0.001$ between groups).

Survival. Mean follow-up duration after follow-up evaluation was $36.8 \pm 11.8$ months (median: 38.0 [27.7-46.1]), and 77.5 \pm 11.0 months (median: 79.7 [69.4-86.2]) since baseline evaluation. Survival status at December 312011 was available for 975 (95.1\%) patients. For the $4.9 \%$ remaining patients who were lost to follow-up and not retrieved in the national register of deceased, last information available was after a $27.4 \pm 11.8$ months mean follow-up duration (median: 25.7 [17.8-35.9]). Thirty-five patients died and seven had liver transplantation during follow-up (Table 2). Forty-two patients were thus considered dead during follow-up, with 21 from liver-related causes. Compared to patients alive at the end of follow-up, patients who died had significantly different baseline characteristics (Table 1): they were more frequently males $(P=0.011)$, had higher age $(P=0.041)$, BMI $(P=0.018)$, baseline or follow-up noninvasive tests results $(P<0.001)$, delta of noninvasive tests $(P \leq 0.005)$, and lower SVR rate $(P=0.033)$. Overall survival significantly decreased as baseline LSM increased (Fig. s2 in Supporting Material).

Overall Accuracy of Noninvasive Tests for the Prediction of Death. Harrell C-index of prognostic models including baseline and follow-up results of fibrosis tests were not significantly different among LSM, APRI, and FIB-4 (see model \#1 in Table 3). After adjustment for SVR, age, sex, BMI, and virus genotype, the difference remained not significant between LSM and FIB-4 models (see models \#2 and 
Table 1. Characteristics of the 1,025 Included Patients

\begin{tabular}{|c|c|c|c|c|}
\hline & All $(n=1,025)$ & Alive at EOF $(n=983)$ & Dead at EOF $(n=42)$ & $P^{*}$ \\
\hline Pessac center (\%) & 83.9 & 84.1 & 78.6 & 0.388 \\
\hline Age (years) & $52.0 \pm 12.0$ & $51.8 \pm 11.9$ & $56.4 \pm 13.9$ & 0.041 \\
\hline Male gender (\%) & 49.7 & 48.8 & 69.0 & 0.011 \\
\hline BMI $\left(\mathrm{kg} / \mathrm{m}^{2}\right)$ & $24.5 \pm 4.0$ & $24.5 \pm 4.1$ & $25.5 \pm 3.0$ & 0.018 \\
\hline Excessive alcohol (\%) & 11.8 & 11.4 & 21.9 & 0.089 \\
\hline Tobacco use (\%) & 47.4 & 47.4 & 46.9 & 1.0 \\
\hline Cannabis use (\%) & 3.3 & 3.3 & 3.6 & 1.0 \\
\hline Diabetes (\%) & 6.8 & 6.6 & 11.9 & 0.200 \\
\hline Hypertension (\%) & 18.3 & 18.2 & 19.5 & 0.837 \\
\hline Virus genotype (\%): & & & & 0.632 \\
\hline-1 & 65.8 & 65.6 & 70.7 & \\
\hline-2 & 13.8 & 13.8 & 12.2 & \\
\hline-3 & 10.2 & 10.1 & 12.2 & \\
\hline-4 & 9.0 & 9.3 & 2.4 & \\
\hline-5 & 1.0 & 0.9 & 2.4 & \\
\hline-6 & 0.2 & 0.2 & 0.0 & \\
\hline Baseline LSM (kPa) & $\begin{array}{c}9.0 \pm 7.9 \\
(6.6 ; 5.1-9.5)\end{array}$ & $\begin{array}{c}8.6 \pm 7.3 \\
(6.4 ; 5.1-9.1)\end{array}$ & $\begin{array}{c}18.4 \pm 13.4 \\
(14.8 ; 8.3-22.0)\end{array}$ & $<0.001$ \\
\hline Baseline LSM (\%) & & & & $<0.001$ \\
\hline$-<7 \mathrm{kPa}$ & 56.0 & 57.8 & 14.3 & \\
\hline$-\geq 7$ and $<14 \mathrm{kPa}$ & 31.3 & 31.4 & 28.6 & \\
\hline - $\geq 14$ and $<20 \mathrm{kPa}$ & 5.9 & 5.0 & 26.2 & \\
\hline$-\geq 20 \mathrm{kPa}$ & 6.8 & 5.8 & 31.0 & \\
\hline Follow-up LSM (kPa) & $\begin{array}{c}9.0 \pm 8.7 \\
(6.2 ; 4.8-8.8)\end{array}$ & $\begin{array}{c}8.4 \pm 7.6 \\
(6.1 ; 4.8-8.5)\end{array}$ & $\begin{array}{c}23.4 \pm 17.3 \\
(19.5 ; 10.1-33.7)\end{array}$ & $<0.001$ \\
\hline Delta LSM (kPa per year) & $\begin{array}{c}0.01 \pm 2.11 \\
(-0.1 ;-0.6-0.4)\end{array}$ & $\begin{array}{c}-0.05 \pm 1.90 \\
(-0.1 ;-0.6-0.4)\end{array}$ & $\begin{array}{c}1.55 \pm 4.70 \\
(0.7 ;-0.3-2.7)\end{array}$ & $<0.001$ \\
\hline Baseline APRI & $\begin{array}{c}0.76 \pm 1.05 \\
(0.43 ; 0.27-0.77)\end{array}$ & $\begin{array}{c}0.69 \pm 0.88 \\
(0.42 ; 0.27-0.73)\end{array}$ & $\begin{array}{c}2.40 \pm 2.44 \\
(1.68 ; 0.52-2.83)\end{array}$ & $<0.001$ \\
\hline Follow-up APRI & $\begin{array}{c}0.81 \pm 1.28 \\
(0.42 ; 0.27-0.76)\end{array}$ & $\begin{array}{c}0.71 \pm 1.05 \\
(0.41 ; 0.27-0.71)\end{array}$ & $\begin{array}{c}3.14 \pm 2.97 \\
(2.18 ; 0.83-4.37)\end{array}$ & $<0.001$ \\
\hline Delta APRI (unit/year) & $\begin{array}{c}0.02 \pm 0.30 \\
(0.01 ;-0.04-0.05)\end{array}$ & $\begin{array}{c}0.01 \pm 0.28 \\
(0.01 ;-0.04-0.05)\end{array}$ & $\begin{array}{c}0.22 \pm 0.54 \\
(0.08 ;-0.05-0.40)\end{array}$ & 0.005 \\
\hline Baseline FIB-4 & $\begin{array}{c}1.84 \pm 1.91 \\
(1.27 ; 0.84-2.03)\end{array}$ & $\begin{array}{c}1.69 \pm 1.54 \\
(1.25 ; 0.83-1.93)\end{array}$ & $\begin{array}{c}5.42 \pm 4.48 \\
(3.93 ; 1.72-9.03)\end{array}$ & $<0.001$ \\
\hline Follow-up FIB-4 & $\begin{array}{c}2.19 \pm 2.65 \\
(1.49 ; 1.04-2.30)\end{array}$ & $\begin{array}{c}1.95 \pm 2.08 \\
(1.45 ; 1.02-2.16)\end{array}$ & $\begin{array}{c}7.75 \pm 6.15 \\
(7.34 ; 2.37-11.74)\end{array}$ & $<0.001$ \\
\hline Delta FIB-4 (unit/year) & $\begin{array}{c}0.10 \pm 0.56 \\
(0.05 ;-0.02-0.16)\end{array}$ & $\begin{array}{c}0.08 \pm 0.49 \\
(0.05 ;-0.02-0.14)\end{array}$ & $\begin{array}{c}0.69 \pm 1.31 \\
(0.30 ;-0.03-1.48)\end{array}$ & $<0.001$ \\
\hline SVR (\%) & 16.4 & 16.9 & 4.8 & 0.033 \\
\hline \multirow[t]{2}{*}{$\begin{array}{l}\text { Time interval between baseline } \\
\text { and follow-up evaluation (months) }\end{array}$} & $40.7 \pm 4.0$ & $40.7 \pm 4.0$ & $41.4 \pm 4.2$ & 0.272 \\
\hline & $(40.1 ; 37.3-43.8)$ & $(40.1 ; 37.2-43.7)$ & $(41.4 ; 37.4-44.8)$ & \\
\hline \multirow{2}{*}{$\begin{array}{l}\text { Follow-up after follow-up } \\
\text { evaluation (months) }\end{array}$} & $36.8 \pm 11.8$ & $37.4 \pm 11.5$ & $23.7 \pm 12.7$ & $<0.001$ \\
\hline & $(38.0 ; 27.7-46.1)$ & $(38.5 ; 28.3-46.4)$ & $(23.6 ; 11.8-31.9)$ & \\
\hline
\end{tabular}

*By Fisher or Mann-Whitney test.

Results are expressed as mean \pm standard deviation (median; $1^{\text {st }}$ and $3^{\text {rd }}$ quartiles). EOF: end of follow-up, BMI: body mass index, LSM: liver stiffness measurement, SVR: sustained viral response, IQR: interquartile range.

\#3 in Table 3). However, adjusted FIB-4 models had significantly higher C-indexes than adjusted APRI models. We thus considered only LSM and FIB-4 for further analyses.

Prediction of Death Using Baseline and Delta LSM. By univariate analysis (Table 4), death was significantly associated with age $(P=0.016)$, male gender $(P=0.012)$, excessive alcohol consumption $(P=0.036)$, baseline LSM $(P<0.001)$, follow-up LSM $(P<0.001)$, delta LSM $(P<0.001)$, and SVR $(P=0.033)$. By multivariate analysis, independent predictors of death were baseline LSM, delta LSM, and SVR. Figure 2 shows Kaplan-Meier curves of overall survival as a function of delta LSM level. Patients whose delta LSM increased by more than $1 \mathrm{kPa} /$ year had a worse overall survival compared to patients whose delta LSM was between -1 and $1 \mathrm{kPa} /$ year $(P<0.001)$ or those who decreased by more than $1 \mathrm{kPa} /$ year $(P=0.012)$. 
Table 2. Causes of Death During Follow-up

\begin{tabular}{ll}
\hline Liver-related deaths $(\mathbf{n = 2 1 )}$ & Deaths unrelated to liver disease $(\mathbf{n = 2 1 )}$ \\
\hline Hepatocellular carcinoma $(n=8)$ & Cardiovascular disease $(n=6)$ \\
Sepsis $(n=3)$ & Non-liver cancer $(n=3)$ \\
Liver failure $(n=2)$ & Stroke $(n=3)$ \\
Hepatorenal syndrome $(n=1)$ & Lung infection $(n=2)$ \\
Liver transplantation* $(n=7)$ & Lymphoma $(n=1)$ \\
& Unknown $(n=6)$ \\
\hline
\end{tabular}

*Patients were censored at transplantation date and considered dead.

Interaction between baseline LSM and delta LSM had borderline significance $(P=0.073)$, whereas it was not significant between SVR and baseline LSM $(P=0.828)$ or delta LSM $(P=0.523)$. Patients with baseline LSM $<7 \mathrm{kPa}$ had excellent prognosis (only $1 \%$ of the 574 died during follow-up) as well as those with baseline LSM $\geq 7 \mathrm{kPa}$ who achieved SVR (2\% of the 102 patients died during follow-up) (Supporting Fig. s3 and Table s2). In the 349 remaining patients with baseline LSM $\geq 7 \mathrm{kPa}$ who did not achieve SVR, interaction between baseline LSM and delta LSM was significant $(P=0.022)$. In the 246 patients with baseline LSM between 7 and $14 \mathrm{kPa}$ who did not achieve SVR, three patient subgroups were identified according to delta LSM (Fig. s4): there was no death during follow-up of the 36 patients who had delta LSM $\leq 1$ $\mathrm{kPa} /$ year, whereas $3 \%$ of the 162 patients with delta LSM between -1 and $1 \mathrm{kPa} /$ year and $12.5 \%$ of the 48 patients with delta LSM $\geq 1 \mathrm{kPa} /$ year died during follow-up. Finally, in the 103 patients with baseline LSM $\geq 14 \mathrm{kPa}$ who did not achieve SVR, two subgroups of patients were identified (Fig. s5): those with delta LSM $\leq 0 \mathrm{kPa} /$ year $(13 \%$ of the 61 patients died during follow-up), and those with delta LSM $>0 \mathrm{kPa} /$ year (36\% of the 42 patients died during follow-up).
Figure 3A shows Kaplan-Meier curves of overall survival as a function of the seven subgroups previously described. Survival was not significantly different across the four first groups (group 1: baseline LSM $<7 \mathrm{kPa}$; group 2: baseline LSM $\geq 7 \mathrm{kPa}$ and SVR during follow-up; group 3: baseline LSM between 7 and 14 $\mathrm{kPa}$, no SVR, and delta LSM $\leq-1 \mathrm{kPa} /$ year; group 4: baseline LSM between 7 and $14 \mathrm{kPa}$, no SVR, and delta LSM between -1 and $1 \mathrm{kPa} /$ year). Interestingly, overall survival was not significantly different between group 5 (baseline LSM between 7 and $14 \mathrm{kPa}$, no SVR, delta $L S M \geq 1 \mathrm{kPa} /$ year) and group 6 (baseline LSM $\geq 14 \mathrm{kPa}$, no SVR, delta LSM $\leq 0 \mathrm{kPa} /$ year). Overall survival in groups 5 and 6 was significantly worse than observed in groups 1-4. Finally, group 7 (baseline LSM $\geq 14 \mathrm{kPa}$, no SVR, delta LSM $>0 \mathrm{kPa} /$ year) had the poorest prognosis in our cohort, significantly worse than all the other six patients groups $(P \leq 0.010)$.

To summarize, patients with a low baseline LSM $(<7 \mathrm{kPa}), \quad$ SVR, or stable/decreasing $(<1 \mathrm{kPa} /$ year $)$ noncirrhosis baseline LSM $(<14 \mathrm{kPa})$ had a similar excellent prognosis. Outcome was significantly impaired in patients with increasing $(\geq 1 \mathrm{kPa} /$ year $)$ baseline fibrotic LSM (7-14 $\mathrm{kPa})$, or with decreasing $(\leq 0 \mathrm{kPa} /$ year) baseline cirrhosis LSM $(\geq 14 \mathrm{kPa})$. The worst prognosis was in patients with increasing $(>0$ $\mathrm{kPa} /$ year) baseline cirrhosis LSM.

Prediction of Death Using Baseline and Delta FIB-4. The same analysis done for LSM was repeated for FIB-4. Univariate and multivariate analysis identified baseline FIB-4 (Ln unit: $P<0.001$, hazard ratio $=4.75$ [95\% CI: 3.30-6.83]) and delta FIB-4 $(P=0.002$, hazard ratio $=1.28$ [95\% CI: $1.10-1.50])$ as independent predictors of death. Overall survival

Table 3. Harrell C-Index for the Prediction of Death by Prognostic Models Including Baseline and Evolution (delta) of Noninvasive Tests Results

\begin{tabular}{|c|c|c|c|}
\hline Fibrosis Test & $\begin{array}{c}\text { Model \#1 } \\
\text { Baseline, }{ }^{*} \text { delta }\end{array}$ & $\begin{array}{c}\text { Model \#2 } \\
\text { Baseline,* delta, SVR }\end{array}$ & $\begin{array}{c}\text { Model \#3 } \\
{\text { Baseline, }{ }^{*} \text { delta, SVR, Age, }}_{\text {Sex, BMI, Virus Genotype }}^{\dagger}\end{array}$ \\
\hline LSM & $0.810[0.716-0.890]$ & $0.824[0.740-0.900]$ & $0.844[0.768-0.908]^{\ddagger}$ \\
\hline FIB4 & $0.824[0.742-0.894]$ & $0.848[0.783-0.907]$ & $0.862[0.800-0.917]$ \\
\hline APRI & $0.795[0.701-0.880]$ & $0.800[0.709-0.881]$ & $0.816[0.735-0.890]$ \\
\hline \multicolumn{4}{|c|}{ Paired-comparisons (p): } \\
\hline LSM vs FIB4 & 0.69 & 0.43 & 0.37 \\
\hline LSM vs APRI & 0.65 & 0.47 & 0.24 \\
\hline FIB4 vs APRI & 0.21 & 0.07 & 0.03 \\
\hline
\end{tabular}

Models \#1 are not adjusted, models \#2 are adjusted for sustained viral response (SVR), and model \#3 are adjusted for SVR, age, sex, body mass index (BMI), and virus genotype.

*Baseline result was introduced as In-transformed for the three noninvasive tests to satisfy the proportional hazards property and/or the linear form assumption.

${ }^{\dagger}$ Virus genotype 1 vs. $2 / 3$ vs. 4/5/6.

${ }^{\ddagger}$ This model was also adjusted for baseline and follow-up interquartile range of LSM result.

LSM: liver stiffness measurement; SVR: sustained viral response. 
Table 4. Predictors of Overall Survival Using LSM Results

\begin{tabular}{|c|c|c|c|c|c|}
\hline \multirow[b]{2}{*}{ Variable } & \multicolumn{2}{|c|}{ Univariate Analysis } & \multicolumn{3}{|c|}{ Multivariate Analysis } \\
\hline & $P^{*}$ & Hazard Ratio (95\% CI) & Step & $\boldsymbol{P}^{\dagger}$ & Hazard Ratio (95\% Cl) \\
\hline Pessac center & 0.283 & $0.67(0.32-1.40)$ & - & - & - \\
\hline Age (years) & 0.016 & $1.03(1.01-1.06)$ & - & - & - \\
\hline Male gender & 0.012 & $2.25(1.17-4.34)$ & - & - & - \\
\hline BMI $\left(\mathrm{kg} / \mathrm{m}^{2}\right)$ & 0.111 & $1.06(0.99-1.13)$ & - & - & - \\
\hline Diabetes & 0.116 & $2.08(0.82-5.29)$ & - & - & - \\
\hline Hypertension & 0.861 & $1.07(0.49-2.32)$ & - & - & - \\
\hline Alcohol abuse & 0.036 & $0.42(0.18-0.97)$ & - & - & - \\
\hline Tobacco use & 0.994 & $1.00(0.50-2.00)$ & - & - & - \\
\hline Cannabis use & 0.832 & $0.81(0.11-5.93)$ & - & - & - \\
\hline Virus genotype: & 0.585 & & - & - & - \\
\hline - 1 versus $2 / 3$ & & 0.97 (0.47-1.99) & & & \\
\hline - 1 versus 4/5/6 & & $0.48(0.11-2.00)$ & & & \\
\hline Baseline LSM (In kPa) & $<0.001$ & $4.27(2.94-6.22)$ & $1^{\text {st }}$ & $<0.001$ & $5.76(3.74-8.87)$ \\
\hline Baseline IQR/M & 0.635 & $0.60(0.07-4.87)$ & - & - & - \\
\hline Follow-up LSM (In kPa) & $<0.001$ & $5.47(3.82-7.84)$ & - & - & - \\
\hline Follow-up IQR/M & 0.909 & $1.22(0.04-38.80)$ & - & - & - \\
\hline Delta LSM (kPa/year) & $<0.001$ & $1.25(1.16-1.36)$ & $2^{\text {nd }}$ & $<0.001$ & $1.19(1.11-1.28)$ \\
\hline Antiviral treatment & 0.305 & $0.73(0.39-1.34)$ & - & - & - \\
\hline SVR & 0.033 & $0.24(0.06-1.00)$ & $3^{\text {rd }}$ & 0.023 & $0.19(0.05-0.80)$ \\
\hline
\end{tabular}

*By Log-rank test on Kaplan Meier curves for qualitative variables and univariate Cox model for quantitative variables.

${ }^{\dagger}$ By multivariate forward stepwise Cox model.

BMI: body mass index, LSM: liver stiffness measurement, SVR: sustained virological response, IQR: interquartile range.

worsened with increasing baseline FIB-4 (Fig. s6) or delta FIB-4 (Fig. s7). After evaluation of interactions between the independent predictors, nine subgroups of patients were finally identified (Supporting Table s3).

Figure 3B shows Kaplan-Meier curves of overall survival as a function of these nine subgroups. Survival was significantly different between groups $1 / 2$ versus 3/4/5 $(P=0.001$ by log-rank test $)$, groups $3 / 4 / 5$ versus $7 \quad(P<0.001)$, and groups 7 versus 6/8/9 $(P=0.038)$. On the other hand, survival was not significantly different between group 1 (low baseline FIB4) and group 2 (intermediate baseline FIB-4 without increase during follow-up, $P=0.620$ ). Survival was also not significantly different between group 3 (intermediate baseline FIB-4 with increase during followup) and groups 4/5 (high baseline FIB-4 without increase, $P=0.456$ ). Finally, survival was not significantly different between group 6 (high baseline FIB-4 with high increase during follow-up) and groups 8/9 (very high baseline FIB-4 with increase during followup, $P=0.760)$.

Survival Without Liver-Related Death. Among the 42 patients who died during follow-up, 21 died from liver-related causes (Table 2). Median baseline
Fig. 2. Kaplan-Meier curves of overall survival as a function of delta LSM $(\mathrm{kPa} /$ year) in the whole cohort.

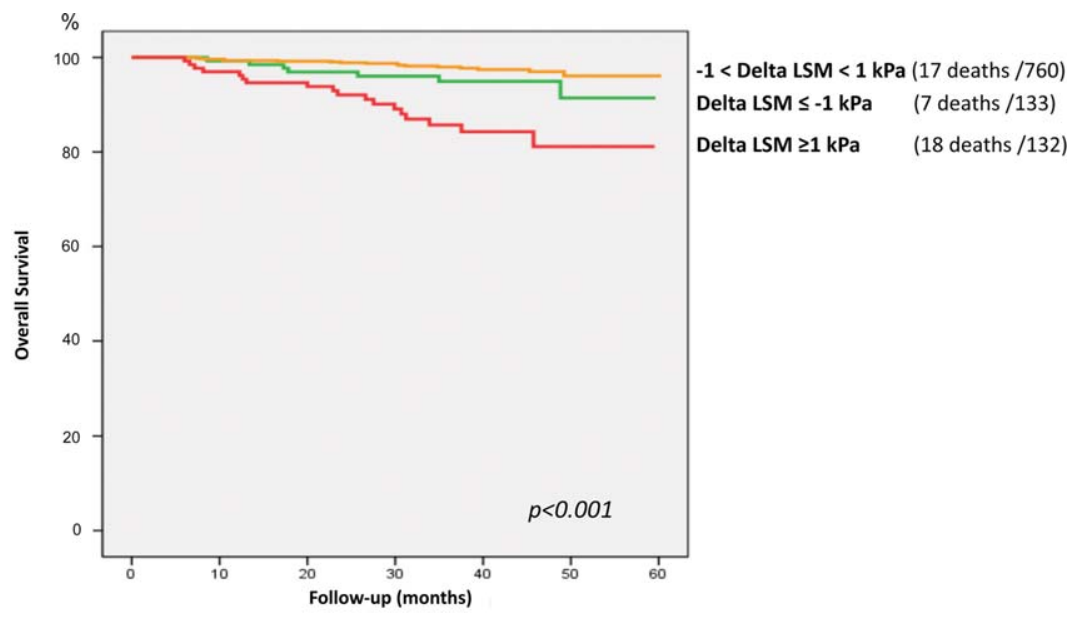

$\begin{array}{lllllll}\text { Delta LSM } \leq-1 & 133 & 132 & 124 & 97 & 61 & 20\end{array}$

$\begin{array}{lllllll}-1<\text { Delta LSM < } 1 \quad 760 & 752 & 691 & 543 & 329 & 84\end{array}$

$\begin{array}{lllllll}\text { Delta } L S M \geq 1 & 132 & 127 & 116 & 85 & 47 & 16\end{array}$ 
Panel $3 \mathrm{~A}$

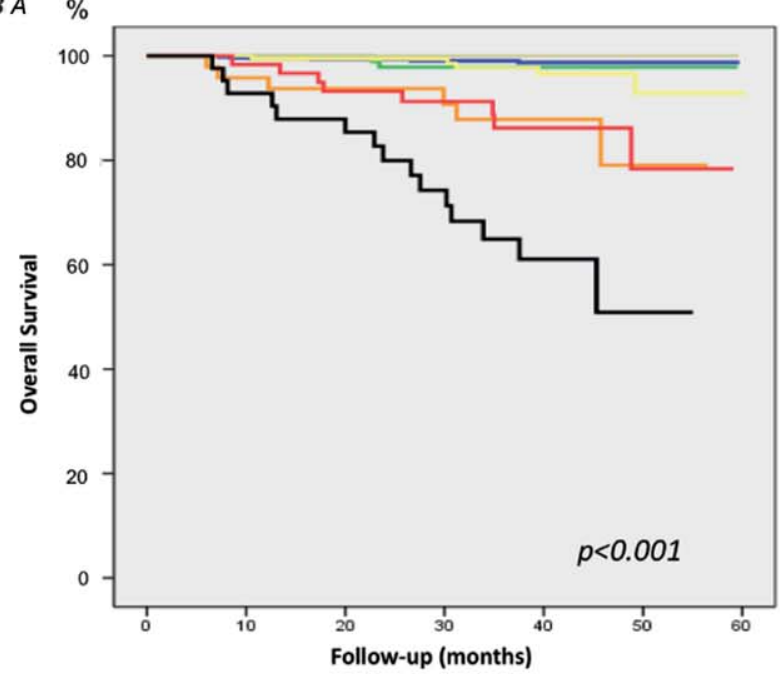

\begin{tabular}{llll}
\hline Group & $\begin{array}{l}\text { Baseline LSM } \\
\text { (kPa) }\end{array}$ & $\begin{array}{l}\text { Delta LSM } \\
\text { (kPa/year) }\end{array}$ & SVR \\
\hline 1 (Blue) & $<7$ & - & - \\
2 (Green) & $\geq 7$ & - & Yes \\
3 (Grey) & 27 and $<14$ & $\leq 1$ & No \\
4 (Yellow) & $\geq 7$ and $<14$ & $>-1$ and $<1$ & No \\
5 (Orange) & $\geq 7$ and $<14$ & $\geq 1$ & No \\
6 (Red) & 214 & $\leq 0$ & No \\
7 (Black) & $\geq 14$ & $>0$ & No \\
\hline
\end{tabular}

$\begin{array}{lcccccc}\text { Blue } & 574 & 567 & 518 & 403 & 243 & 66 \\ \text { Green } & 102 & 102 & 98 & 76 & 47 & 14 \\ \text { Grey } & 36 & 36 & 35 & 24 & 16 & 6 \\ \text { Yellow } & 162 & 162 & 153 & 126 & 80 & 19 \\ \text { Orange } & 48 & 46 & 41 & 31 & 16 & 6 \\ \text { Red } & 61 & 60 & 52 & 40 & 22 & 7 \\ \text { Black } & 42 & 38 & 34 & 25 & 13 & 2\end{array}$

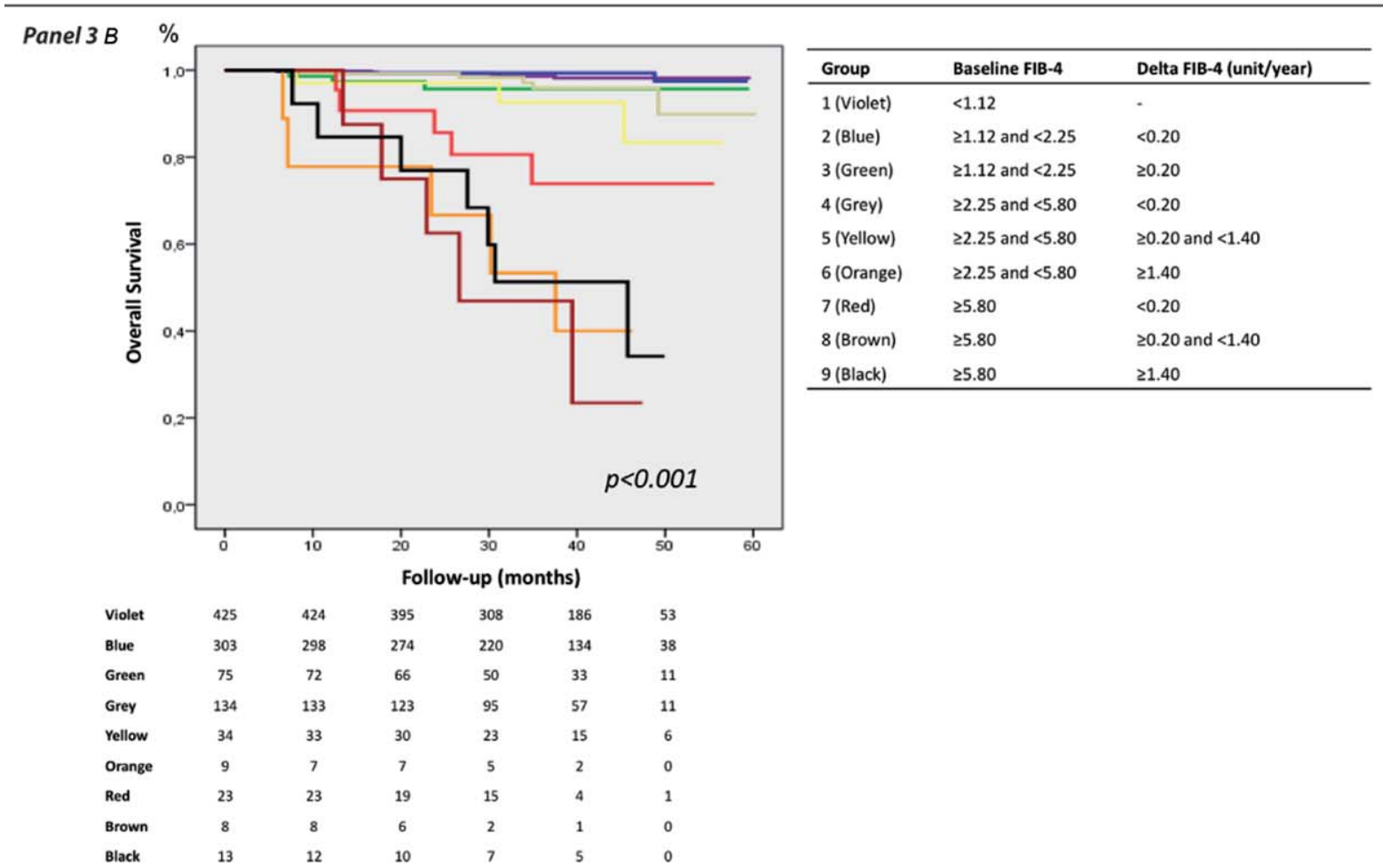

Fig. 3. Kaplan-Meier curves of overall survival as a function of patients subgroups defined by baseline LSM, delta LSM, and sustained viral response $(A)$, or by baseline and delta FIB-4 (B).

LSM was significantly different between patients who died from a liver-related cause and those who died from a nonliver-related cause, respectively: $18.5 \mathrm{kPa}$ [11.1-30.7] versus $12.8 \mathrm{kPa}$ [6.1-18.9] $(P=0.036)$. Survival without liver-related death significantly decreased as baseline LSM increased (Fig. s8 and Table s1). Survival without liver-related death as a function of the seven LSM groups (previously defined according to baseline LSM, delta LSM, and SVR) or the nine FIB-4 groups (previously defined by baseline and delta 
FIB-4) is depicted in Fig. s9. These figures show similar trends than those observed for overall survival.

\section{Discussion}

To our knowledge, this is the first study showing that evolution of noninvasive tests of liver fibrosis is predictive of survival in CHC. Monitoring patients with LSM allows a prediction of overall survival and survival without liver-related death. Survival decreases as delta LSM increases, especially in patients with baseline LSM $>7 \mathrm{kPa}$. Global evaluation using Harrell Cindexes of multivariate predictive models showed that FIB-4 was as accurate as LSM for the prediction of death, and significantly more accurate than APRI. As with LSM, baseline and delta FIB-4 identified patient subgroups with significantly different prognoses. Our study highlights the major importance of noninvasive first evaluation, fibrosis monitoring, and antiviral treatment. It validates LSM as a strong predictive noninvasive tool for the follow-up of patients with chronic hepatitis C.

Median follow-up in our study is 79.7 months, with a very low rate of loss to follow-up (5\%). In this long-term follow-up, patients with a very bad prognosis may have been missed, especially those excluded for having previous liver-related complications, those who died before follow-up LSM, those who could not have an LSM performed due to ascites, or poor general status. Some patients did not have follow-up LSM, due to failure or unreliable follow-up LSM, or because they stopped their follow-up in the investigator centers. For most of these patients, a bad outcome could be predicted with simple methods such as Child-Pugh or MELD scores. We did not use these two scores in our study because few patients were cirrhotic at baseline $(12.7 \%$ had baseline LSM $\geq 14 \mathrm{kPa})$. Furthermore, these scores increase in a small proportion of patients, usually those with high LSM or high delta LSM.

We arbitrarily chose a second evaluation 3 years after baseline. We considered this delay to be long enough to observe significant variations in LSM, the impact of a complete and efficient antiviral treatment, and to obtain a sufficient cohort to describe survival with a long follow-up. Optimal delay for LSM monitoring remains to be defined. Patients with a low baseline LSM, or with SVR, should be monitored with a 3-year second LSM, as shown in our study. Patients with high baseline LSM or comorbidities could be monitored every year, in order to identify and treat a more aggressive disease. Future studies are needed to determine delays for LSM monitoring, according to liver characteristics, but also patient characteristics.

Our study exhibited a major impact of SVR in patient's outcome. First, SVR had no influence on overall survival in patients with low LSM at baseline, confirming the role of LSM in starting treatments. Second, patients with fibrosis or cirrhosis at baseline and SVR during follow-up had a very different prognosis compared to non-SVR patients, illustrating the need for retreatment in experienced patients, and the need for the development and commercialization of new molecules as quickly as possible.

Our final data on overall survival have strong implications for clinical practice. Patients with a low baseline LSM $(<7 \mathrm{kPa})$, SVR, or stable/decreasing $(\leq 1$ $\mathrm{kPa} /$ year $)$ noncirrhosis baseline LSM $(<14 \mathrm{kPa})$ have an excellent prognosis in terms of overall survival, with a very low rate of liver-related death. Physicians may adapt the frequency of monitoring in these patients and not insist on antiviral treatment. Since patients with initial significant fibrosis who display decreasing LSM also have excellent prognosis, we illustrate the need for handling comorbidities, i.e., any other cause of higher LSM that could decrease with treatment, usually alcoholic liver disease and nonalcoholic steatohepatitis. Conversely, our results show that patients with a presumed liver significant fibrosis (LSM between 7 and $14 \mathrm{kPa}$ ) and increasing LSM $\geq 1 \mathrm{kPa} /$ year had a similar prognosis to patients with presumed cirrhosis (LSM $\geq 14 \mathrm{kPa})$ and decreasing LSM $(<0$ $\mathrm{kPa} /$ year $)$. Finally, patients with increasing $(>0 \mathrm{kPa} /$ year) baseline cirrhosis LSM have the worse prognosis, since cirrhosis patients with a progressive disease (whatever the cause, hepatitis $\mathrm{C}$ or comorbidities) are strongly exposed to the liver-related complications. According to these results, we propose a clinical management algorithm, using baseline LSM, LSM evolution, and SVR achievement for the prediction of prognosis and patient management in $\mathrm{CHC}$ (Fig. 4).

FIB-4 appears as accurate as LSM for the prediction of death in our cohort. Indeed, the Harrell C-index of prognostic models derived from LSM or FIB-4 results were not significantly different (Table 3), and survival among the prognostic subgroups identified by LSM and FIB-4 showed a similar pattern (Fig. 3). FIB-4 has the strong advantages of being cheap, easy-to-calculate, and available to all practitioners. Nevertheless, other blood fibrosis tests have been developed for the noninvasive diagnosis of liver fibrosis in CHC: Fibrotest, FibroMeter, Hepascore, or ELF. These blood tests are more complex to calculate and more expensive than FIB-4, but they are also more accurate for the 


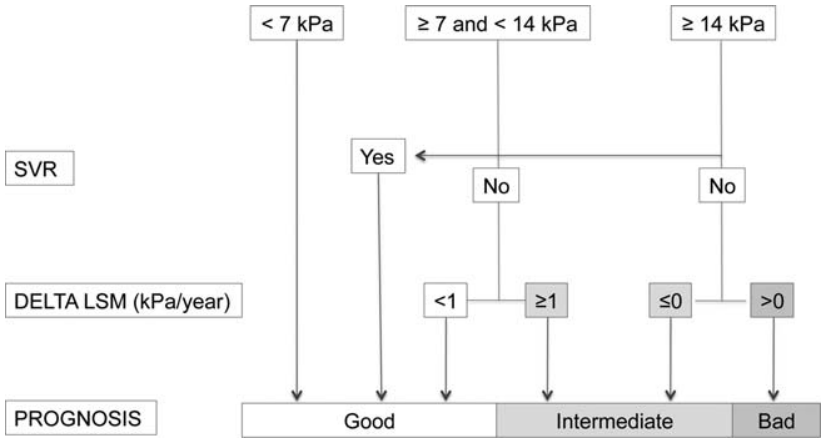

Fig. 4. Algorithm using baseline LSM, delta LSM, and SVR for the assessment of prognosis in patients with chronic hepatitis C. LSM: liver stiffness measurement, SVR: sustained viral response.

diagnosis of fibrosis. ${ }^{40}$ Knowing that prognosis in $\mathrm{CHC}$ is linked to liver fibrosis, noninvasive tests that are better calibrated to this lesion may have better accuracy for the prognosis assessment. Further studies that evaluate the prognostic significance of the evolution of these blood tests are thus required.

Compared to FIB-4, LSM is expensive but has some particular advantages for diagnosis and prognostic assessment in CHC. Indeed, LSM is one of the best-validated methods for these two aims in almost every chronic liver disease, with good applicability and reproducibility. Interestingly, calculated baseline LSM cutoffs in our study (7.0 and $14.0 \mathrm{kPa})$ were the same as those usually accepted for the diagnosis of significant fibrosis and cirrhosis in CHC. ${ }^{16,36,37}$ This shows that LSM displays a continuum between diagnosis of liver fibrosis and prognosis assessment in $\mathrm{CHC}$. Another advantage is that LSM provides immediate results, thus with the possibility to refine the patient management during the consultation.

Finally, since the Controlled Attenuation Parameter (CAP) is now coupled with LSM, it is possible to have a quantitative measurement of steatosis at the same time of fibrosis evaluation. ${ }^{41}$ As liver steatosis is associated with worse prognosis in $\mathrm{CHC},{ }^{42}$ further studies will have to determine if CAP measurement helps to refine prognosis assessment by LSM.

Our results are of course a proof of concept, and more studies are required to sharpen the information given by repeated measurements, especially in terms of survival without liver complication, to estimate the risks of ascites, encephalopathy, variceal bleeding, or hepatocellular carcinoma. Large prospective multicenter studies will be needed to define these predictive values, assess the influence of LSM reproducibility and reliability, and evaluate the cost-effectiveness of noninvasive monitoring. Furthermore, in a world where more $\mathrm{CHC}$ will be "curable" with expensive antiviral treatments, the prediction of prognosis will probably help physicians to identify patients "worth being treated."

With regard to liver monitoring, repeated noninvasive tests of liver fibrosis may help to change the standard care of patients with cirrhosis. Indeed, regression of liver fibrosis in $\mathrm{CHC}$ patients is associated with an excellent prognosis. ${ }^{43}$ Finally, data about monitoring by noninvasive fibrosis tests are needed for the other main causes of chronic liver diseases, especially the "hard to treat" nonalcoholic fatty liver disease, in order to improve recommendations, start hepatocellular carcinoma screening, and select patients for therapeutic clinical trials.

In conclusion, the evolution over time of LSM and FIB-4 results is predictive of long-term survival in patients with $\mathrm{CHC}$ and strongly helps physicians in the prediction of patient prognosis. All $\mathrm{CHC}$ patients should undergo a noninvasive evaluation of liver fibrosis at baseline, but noninvasive tests need to be repeated, especially in patients with significant fibrosis or cirrhosis, to better predict their outcome, help in the decision of antiviral treatment, handle comorbidities, and decide on liver transplantation. As indicated in Fig. 4, baseline measurement, evolution, and antiviral response are three main tools for the management of CHC in 2013.

Author Contributions: Julien Vergniol: study concept and design, acquisition of data, analysis and interpretation of results, drafting of the article, statistical analysis; Jérôme Boursier: study concept and design, acquisition of data, analysis and interpretation of results, statistical analysis; Clelia Coutzac: acquisition of data, technical support; Sandrine Bertrais: analysis and interpretation of results, statistical analysis, RNIPP register; Juliette Foucher: acquisition of data, technical support; Camille Angel: acquisition of data, technical support; Faiza Chermak: acquisition of data, technical support; I. Fouchard Hubert: acquisition of data, technical support; Wassil Merrouche: acquisition of data, technical support; Frederic Oberti: acquisition of data, technical support; Victor de Lédinghen: study concept and design, statistical analysis, study supervision; Paul Calès: study concept and design, statistical analysis.

\section{References}

1. Bedossa P, Dargere D, Paradis V. Sampling variability of liver fibrosis in chronic hepatitis C. Hepatology 2003;38:1449-1457.

2. Kamath PS, Kim WR. The model for end-stage liver disease (MELD). Hepatology 2007;45:797-805.

3. Pugh RN, Murray-Lyon IM, Dawson JL, Pietroni MC, Williams R. Transection of the oesophagus for bleeding oesophageal varices. $\mathrm{Br} \mathrm{J}$ Surg 1973;60:646-649. 
4. Nunes D, Fleming C, Offner G, Craven D, Fix O, Heeren T, et al. Noninvasive markers of liver fibrosis are highly predictive of liverrelated death in a cohort of HCV-infected individuals with and without HIV infection. Am J Gastroenterol 2010;105:1346-1353.

5. Sterling RK, Lissen E, Clumeck N, Sola R, Correa MC, Montaner J, et al. Development of a simple noninvasive index to predict significant fibrosis in patients with HIV/HCV coinfection. Hepatology 2006;43: $1317-1325$.

6. Wai CT, Greenson JK, Fontana RJ, Kalbfleisch JD, Marrero JA, Conjeevaram HS, et al. A simple noninvasive index can predict both significant fibrosis and cirrhosis in patients with chronic hepatitis C. Hepatology 2003;38:518-526.

7. Naveau S, Gaude G, Asnacios A, Agostini H, Abella A, Barri-Ova N, et al. Diagnostic and prognostic values of noninvasive biomarkers of fibrosis in patients with alcoholic liver disease. Hepatology 2009;49:97-105.

8. Ngo Y, Munteanu M, Messous D, Charlotte F, Imbert-Bismuth F, Thabut D, et al. A prospective analysis of FibroTest-Actitest-FibroSure prognostic value in patients with chronic hepatitis $\mathrm{C}$ (CHC). HepATOLOGY 2005;42:438A.

9. Ngo Y, Benhamou Y, Thibault V, Ingiliz P, Munteanu M, Lebray P, et al. An accurate definition of the status of inactive hepatitis B virus carrier by a combination of biomarkers (FibroTest-ActiTest) and viral load. PLoS One 2008;3:e2573.

10. Ngo Y, Munteanu M, Messous D, Charlotte F, Imbert-Bismut F, Thabut $\mathrm{D}$, et al. A prospective analysis of the prognostic value of biomarkers (FibroTest) in patients with chronic hepatitis C. Clin Chem 2006;52:1887-1896.

11. Morra R, Lebray P, Ingiliz P, Ngo Y, Munteanu M, Ratziu V, et al. FibroTest has better diagnostic and prognostic values than the aspartate aminotransferase-to-platelet ratio index in patients with chronic hepatitis C. Hepatology 2008;47:353-354; author reply 354-356.

12. Parkes J, Roderick P, Harris S, Day C, Mutimer D, Collier J, et al. Enhanced liver fibrosis test can predict clinical outcomes in patients with chronic liver disease. Gut 2009;59:1245-1251.

13. Mayo MJ, Parkes J, Adams-Huet B, Combes B, Mills AS, Markin RS, et al. Prediction of clinical outcomes in primary biliary cirrhosis by serum enhanced liver fibrosis assay. Hepatology 2008;48:15491557.

14. Forns X, Ampurdanes S, Llovet JM, Aponte J, Quinto L, MartinezBauer $\mathrm{E}$, et al. Identification of chronic hepatitis $\mathrm{C}$ patients without hepatic fibrosis by a simple predictive model. Hepatology 2002;36: 986-992.

15. Wong VW, Vergniol J, Wong GL, Foucher J, Chan HL, Le Bail B, et al. Diagnosis of fibrosis and cirrhosis using liver stiffness measurement in nonalcoholic fatty liver disease. HePaTOLOGy 2010;51:454-462.

16. Castera L, Vergniol J, Foucher J, Le Bail B, Chanteloup E, Haaser M, et al. Prospective comparison of transient elastography, Fibrotest, APRI, and liver biopsy for the assessment of fibrosis in chronic hepatitis C. Gastroenterology 2005;128:343-350.

17. de Ledinghen V, Douvin C, Kettaneh A, Ziol M, Roulot D, Marcellin P, et al. Diagnosis of hepatic fibrosis and cirrhosis by transient elastography in HIV/hepatitis C virus-coinfected patients. J Acquir Immune Defic Syndr 2006;41:175-179.

18. de Ledinghen V, Vergniol J. Transient elastography for the diagnosis of liver fibrosis. Expert Rev Med Devices 2010;7:811-823.

19. Fraquelli M, Rigamonti C, Casazza G, Conte D, Donato MF, Ronchi G, et al. Reproducibility of transient elastography in the evaluation of liver fibrosis in patients with chronic liver disease. Gut 2007;56:968-973.

20. Friedrich-Rust M, Ong MF, Martens S, Sarrazin C, Bojunga J, Zeuzem $S$, et al. Performance of transient elastography for the staging of liver fibrosis: a meta-analysis. Gastroenterology 2008;134:960-974.

21. Foucher J, Chanteloup E, Vergniol J, Castera L, Le Bail B, Adhoute X, et al. Diagnosis of cirrhosis by transient elastography (FibroScan): a prospective study. Gut 2006;55:403-408.

22. Fung J, Lai CL, Seto WK, Wong DK, Yuen MF. Prognostic significance of liver stiffness for hepatocellular carcinoma and mortality in HBeAg-negative chronic hepatitis B. J Viral Hepat 2010.
23. Masuzaki R, Tateishi R, Yoshida H, Goto E, Sato T, Ohki T, et al. Prospective risk assessment for hepatocellular carcinoma development in patients with chronic hepatitis $\mathrm{C}$ by transient elastography. HepatoLOGY 2009;49:1954-1961.

24. de Ledinghen V, Vergniol J, Barthe C, Foucher J, Chermak F, Le Bail $\mathrm{B}$, et al. Noninvasive tests for fibrosis and liver stiffness predict 5-year survival of patients chronically infected with hepatitis B virus. Aliment Pharmacol Ther 2013;37:979-988.

25. Vergniol J, Foucher J, Terrebonne E, Bernard PH, le Bail B, Merrouche W, et al. Noninvasive tests for fibrosis and liver stiffness predict 5-year outcomes of patients with chronic hepatitis C. Gastroenterology 2011;140:1970-1979, 1979 e1971-1973.

26. Poynard T, Bedossa P, Opolon P. Natural history of liver fibrosis progression in patients with chronic hepatitis C. The OBSVIRC, METAVIR, CLINIVIR, and DOSVIRC groups. Lancet 1997;349:825-832.

27. Wong GL, Wong VW, Choi PC, Chan AW, Chim AM, Yiu KK, et al. On-treatment monitoring of liver fibrosis with transient elastography in chronic hepatitis B patients. Antivir Ther 2011;16:165-172.

28. Enomoto M, Mori M, Ogawa T, Fujii H, Kobayashi S, Iwai S, et al. Usefulness of transient elastography for assessment of liver fibrosis in chronic hepatitis B: Regression of liver stiffness during entecavir therapy. Hepatol Res 2010;40:853-861.

29. Fransen van de Putte DE, Fischer K, de Knegt RJ, Posthouwer D, van Erpecum KJ, Mauser-Bunschoten EP. Liver stiffness measurements to assess progression of fibrosis in $\mathrm{HCV}$-infected patients with inherited bleeding disorders. Haemophilia 2011;17:e975-980.

30. Cales P, Zarski JP, Chapplain JM, Bertrais S, Sturm N, Michelet C, et al. Fibrosis progression under maintenance interferon in hepatitis $\mathrm{C}$ is better detected by blood test than liver morphometry. J Viral Hepat 2012;19:e143-153.

31. Kim BK, Oh HJ, Park JY, Kim do Y, Ahn SH, Han KH, et al. Early on-treatment change in liver stiffness predicts development of liverrelated events in chronic hepatitis B patients receiving antiviral therapy. Liver Int 2013;33:180-189.

32. Corpechot C, Carrat F, Poujol-Robert A, Gaouar F, Wendum D, Chazouilleres O, et al. Noninvasive elastography-based assessment of liver fibrosis progression and prognosis in primary biliary cirrhosis. Hepatology 2012;56:198-208.

33. Boursier J, Zarski JP, de Ledinghen V, Rousselet MC, Sturm N, Lebail $\mathrm{B}$, et al. Determination of reliability criteria for liver stiffness evaluation by transient elastography. Hepatology 2013;57:1182-1191.

34. Castera L, Foucher J, Bernard PH, Carvalho F, Allaix D, Merrouche W, et al. Pitfalls of liver stiffness measurement: a 5-year prospective study of 13,369 examinations. Hepatology 2010;51:828-835.

35. EASL Clinical Practice Guidelines: management of hepatitis C virus infection. J Hepatol 2011;55:245-264.

36. Bureau C, Metivier S, Peron JM, Selves J, Robic MA, Gourraud PA, et al. Transient elastography accurately predicts presence of significant portal hypertension in patients with chronic liver disease. Aliment Pharmacol Ther 2008;27:1261-1268.

37. Ziol M, Handra-Luca A, Kettaneh A, Christidis C, Mal F, Kazemi F, et al. Non-invasive assessment of liver fibrosis by measurement of stiffness in patients with chronic hepatitis C. Hepatology 2005;41:48-54.

38. Harrell FE Jr, Lee KL, Mark DB. Multivariable prognostic models: issues in developing models, evaluating assumptions and adequacy, and measuring and reducing errors. Stat Med 1996;15:361-387.

39. Empana JP, Tafflet M, Escolano S, Vergnaux AC, Bineau S, Ruidavets JB, et al. Predicting CHD risk in France: a pooled analysis of the D.E.S.I.R., Three City, PRIME, and SU.VI.MAX studies. Eur J Cardiovasc Prev Rehabil 2011;18:175-185.

40. Boursier J, de Ledinghen V, Zarski JP, Rousselet MC, Sturm N, Foucher J, et al. A new combination of blood test and fibroscan for accurate non-invasive diagnosis of liver fibrosis stages in chronic hepatitis C. Am J Gastroenterol 2011;106:1255-1263.

41. de Ledinghen V, Vergniol J, Foucher J, Merrouche W, le Bail B. Noninvasive diagnosis of liver steatosis using controlled attenuation parameter (CAP) and transient elastography. Liver Int 2012;32:911-918. 
42. Adinolfi LE, Restivo L, Marrone A. The predictive value of steatosis in hepatitis C virus infection. Expert Rev Gastroenterol Hepatol 2013;7:205-213.

43. Mallet V, Gilgenkrantz H, Serpaggi J, Verkarre V, Vallet-Pichard A, Fontaine $\mathrm{H}$, et al. Brief communication: the relationship of regression of cirrhosis to outcome in chronic hepatitis C. Ann Intern Med 2008; 149:399-403.

\section{Supporting Information}

Additional Supporting Information may be found in the online version of this article at the publisher's website. 